\title{
Psychometric properties of Persian version of Beck depression inventory in coronary patients
}

\author{
Seyed Mojtaba Ahmadi, Abbas Masjedi Arani*, Maryam Bakhtiari, \\ Mohamad Hasan Davazdah Emamy, and Rasul Mohamadian
}

ABSTRACT

\section{BACKGROUND}

Obtaining psychometric properties regarding specific populations increases diagnostic accuracy and reduces economic health burdens. Beck depression inventory-second version (BDI-II) is useful for the screening and assessment of depression in clinical and research settings. The aim of the present study was to investigate the psychometric properties of the Persian (Farsi) version of BDI-II in patients with coronary heart disease (CHD).

\section{METHODS}

A cross-sectional study was conducted on 284 patients with CHD admitted to Imam Ali Hospital in Kermanshah. They were first given a structured clinical interview (SCID-I) and then were asked to complete the Beck depression inventory-II (BDI-II), patient health questionnaire 9 (PHQ-9) and generalized anxiety disorder 7 (GAD-7). Data were analyzed by descriptive statistics, Cronbach's $\alpha$, Spearman's correlation coefficient, exploratory factor analysis and receiver operating characteristic curve (ROC).

\section{RESULTS}

The internal consistency measured using Cronbach's alpha was 0.90. The obtained correlation of BDI-II with PHQ-9 and GAD-7 was 0.74 and 0.65 , respectively $(p<0.001)$. Factor analysis of the inventory revealed 5 factors, namely cognitive, somatic, impaired performance, negative attitude to self and , and self punishment respectively. The cut-off point for CHD patients was 11 with sensitivity of 0.78 and specificity of 0.81 according to the Youden index and 10 with sensitivity of 0.80 and specificity of 0.77 according to the two-stage approach. The area under the curve was $0.86(95 \%$ Confidence Interval 0.82-0.90).

\section{CONCLUSION}

The Persian version of the BDI-II possesses the acceptable psychometric properties that can be used to screen depression in CHD patients.

Keywords: Beck depression inventory-II, depression, coronary disease, psychometrics, sensitivity and specificity
Department of Clinical Psychology, School of Medicine, Shahid Beheshti University of Medical Sciences,

Tehran, Iran

Correspondence:

Abbas Masjedi Arani

*Department of Clinical Psychology, School of Medicine, Shahid Beheshti University of Medical Sciences,

Tehran, Iran

Email: doctormasjedi@yahoo.com, Tel: +09125752870

Date of first submission, January 13, 2019

Date of final revised submission, March 20, 2019

Date of acceptance, March 22, 2019

This open access article is distributed under a Creative Commons AttributionNon Commercial-Share Alike 4.0 International License

Cite this article as: Ahmadi SM, Masjedi Arani A, Bakhtiari M, et al. Psychometric properties of persian version of beck depression inventory in coronary patients. Univ Med 2019; 38:33-40. doi: 10.18051/UnivMed. 2019.v38.33-40 


\section{INTRODUCTION}

Depression is a comorbid disorder to severe physical problems, ${ }^{(1)}$ such as cancer ${ }^{(2)}$ and cardiovascular problems. ${ }^{(3,4)}$ Depression is highly witnessed among coronary patients. A study in China estimated the prevalence to be between $34.6 \%$ to $45.8 \% .^{(5)}$ Research carried out in Iran reported the prevalence of depression among coronary patients to be $66 \%{ }^{(6)}$ Depression is one of the cardiovascular risk factors which has been reported to be linked to negative treatment results and even to increased death rates among such patients. ${ }^{(7,8)}$ In case patients with cardiovascular problems are diagnosed with depression, there is an urgent need for psychotherapy.(9) Rapid and accurate diagnosis of depression in coronary patients is one of the pressing priorities. Interviews which lead to diagnosis impose time and cost restrictions on the healthcare system so the need for an accurate and specialized inventory to help with diagnosis is strongly felt. Various depression inventories are available, such as Beck depression inventory (BDI), properties patient health questionnaire 9 (PHQ-9), cardiac depression scale (CDS), and each displays different

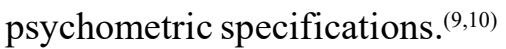

Regarding the major importance attached to the case of coronary patients, the need is felt to consider different depression inventories so that the best inventory with the most accurate sensitivity can be singled out and introduced as the appropriate choice for such patients. Beck depression inventory is an acceptable one, approved and suggested by the National Heart Foundation of Australia. ${ }^{(9)}$ Although this questionnaire has shown acceptable reliability and validity in other countries for measuring depression in cardiac patients such as Indonesia (11) and Canada, ${ }^{(12)}$ the need to investigate the reliability, validity, cut-off point, sensitivity, and specificity of BDI-II in Iranian cardiac patients is strongly felt.

As it is well proved that depression symptoms can surface differently in differing cultures, ${ }^{(13)}$ it is necessary to investigate the reliability and validity of the BDI in different countries and with different populations.

Beck depression inventory -second edition (BDI-II) has been frequently used in various groups, including heart patients in Iran. ${ }^{(14-16)}$ However, in all of the studies, the psychometric properties obtained in the general population or the general properties of the questionnaire have been used. That is the reason why the psychometric properties of various groups may be different and one of the limitations we encounter is the restricted ability to generalize data for example. Wang et al. ${ }^{(17)}$ showed that the cutoff points for screening for depression in various populations are different, and the cut-off point for the BDI in the general population is in the lower range (from 10-16) compared to the clinical population (from 7-20) and the psychiatric population (from 19-31). In Iran, there is no study that has addressed the psychometric properties of this questionnaire in patients with coronary artery disease.

It is thus mandatory to investigate the psychometric properties and the diagnostic cutoff points of the inventory among coronary patients in Iran. Accordingly, the present research aims at investigating the reliability, validity, and cut-off point of the BDI-II in Iranian coronary patients.

\section{METHODS}

\section{Participants and procedures}

Among patients referred to Imam Ali Hospital in Kermanshah from June 22, 2018 to November 22, 2018, 289 patients with coronary heart disease were selected as samples. Excluded were patients with thyroid dysfunction, cognitive disorders such as dementia or Alzheimer's disease, records of brain strokes, severe psychological problems like psychotic symptoms and dissociative identity disorder as well as those who, due to severe heart problems, could not fill out questionnaires. Following briefing of the participants and acquiring their consent, clinical structured interviews were conducted by two 
psychologists. The participants then completed the PHQ-9, GAD-7, and BDI-II questionnaires.

\section{Measurements}

Structured clinical interview for DSM-5 (SCID): the structured clinical interview for DSM-V is the semi-structured interview for main diagnosis of DSM-5 (previously placed on the first axis). This instrument needs to be implemented by a clinical psychologist or a trained psychological health specialist familiar with diagnostic scales and classification of disorders in DSM-5. ${ }^{(18)}$

\section{Depression}

Beck depression inventory (BDI-II) is a 21question inventory that measures the severity of depression. The inventory uses a 4-point Likert scale that assigns a value of 0 to 3 to every answer. The higher the score, the more severe the depression would be. The total score ranges from 0 to 63 . Scores 0 to 13 indicate minimal depression, scores 14 to 19 indicate mild depression, scores 20 to 28 indicate moderate depression and scores 29 to 63 indicate severe depression. ${ }^{(19)}$

Patient health questionnaire-9 (PHQ-9) is a self-report questionnaire which is designed to diagnose based on the Diagnostic and Statistical Manual for Mental Disorders-IV (DSM-IV). It has 9 questions and is derived from the complete version of PHQ. Participants need to report how they have felt over the past two weeks on a 4point Likert scale ranging from not at all (0), several days (1), more than half the days (2), almost every day (3) and the total score ranges from 0 to $6 .^{(20)}$

\section{Anxiety}

Generalized anxiety disorder 7 (GAD-7) is a self-report seven-item questionnaire that was devised by Spitzer et al. ${ }^{(21)}$ It basically includes 9 items and is based on DSM. It is scored according to a 4-point Likert scale from 0 to 3 (not at all $=$ 0 , several days $=1$, more than half the days $=2$, and nearly every day $=3$ ). The obtained total score is between 0 to 21 and the questionnaire is of a sensitivity of 0.89 and specificity of 0.82 at the cut-off point of 10 .

\section{Data analysis}

To analyze the data SPSS software version 21 was implemented. Cronbach's alpha was used to monitor the reliability. To investigate the validity, criterion validity based on the correlation between PHQ-9 and GAD-7 was used and to do so, Pearson correlation coefficient was calculated. To investigate the construct validity, exploratory factor analysis was performed. To interpret the ROC curve and obtain the best cut-off point, two methods suggested by Lowe et al. ${ }^{(22)}$ were used. In the first method, maximal Youden Index (sensitivity + specificity-1) was implemented. The second method implemented a two-stage approach for screening depression disorder. In this method, the cut-off point is obtained with maximum sensitivity and specificity, higher than 0.75 . The two-stage approach sounds more congenial to the clinical situation where the positive results of screening are usually followed by long diagnostic interviews and treatment in case they are rendered necessary. The area under the curve (AUC) was considered as the accuracy of scale.

\section{Ethical considerations}

This research project was approved by the Ethics Committee of the Shahid Beheshti University of Medical Silences under the code of ethics IR.SBMU.MSPREC.1396.286. As for those patients showing severe depression in clinical interviews, psychiatric counseling was requested after informing the cardiologic section of the hospital and the related specialist.

\section{RESULTS}

\section{Characteristics of the subjects}

Two hundred eighty-four patients admitted to Kermanshah's Imam Ali Hospital who were diagnosed with CHD filled out the questionnaires. The age range of the participants was $59.78 \pm$ 10.19 years and there was an almost equal gender distribution, with 155 male participants making up 
Table 1. Item analysis of BDI-II

\begin{tabular}{|c|c|c|c|c|c|c|}
\hline Number & $\begin{array}{c}\text { Item } \\
\text { description }\end{array}$ & $\begin{array}{c}\text { Scale } \\
\text { Mean } \\
\text { if Item } \\
\text { Deleted }\end{array}$ & $\begin{array}{c}\text { Scale } \\
\text { Variance } \\
\text { if Item } \\
\text { Deleted }\end{array}$ & $\begin{array}{l}\text { Corrected } \\
\text { Item-Total } \\
\text { Correlation }\end{array}$ & $\begin{array}{c}\text { Squared } \\
\text { Multiple } \\
\text { Correlation }\end{array}$ & $\begin{array}{l}\text { Cronbach's } \\
\text { Alpha if } \\
\text { Item } \\
\text { Deleted }\end{array}$ \\
\hline BDI 1 & Sadness & 9.2784 & 66.745 & 0.739 & 0.601 & 0.885 \\
\hline BDI 2 & Pessimism & 9.5804 & 69.016 & 0.577 & 0.408 & 0.890 \\
\hline BDI 3 & Past failure & 9.4510 & 68.359 & 0.612 & 0.474 & 0.889 \\
\hline BDI 4 & Loss of pleasure & 9.3451 & 65.605 & 0.540 & 0.415 & 0.891 \\
\hline BDI 5 & Guilty feelings & 9.5412 & 70.438 & 0.421 & 0.389 & 0.894 \\
\hline BDI 6 & Punishment feelings & 9.6627 & 70.516 & 0.442 & 0.390 & 0.893 \\
\hline BDI 7 & Self-dislike & 9.2588 & 65.232 & 0.495 & 0.426 & 0.894 \\
\hline BDI 8 & Self-critical & 9.5490 & 69.123 & 0.560 & 0.442 & 0.890 \\
\hline BDI 9 & Suicidal thoughts & 9.8392 & 72.411 & 0.399 & 0.310 & 0.894 \\
\hline BDI 10 & Crying & 9.3922 & 69.200 & 0.432 & 0.268 & 0.894 \\
\hline BDI 11 & Agitation & 9.3333 & 66.900 & 0.651 & 0.534 & 0.887 \\
\hline BDI 12 & Loss of interest & 9.5176 & 67.896 & 0.727 & 0.603 & 0.886 \\
\hline BDI 13 & Indecisiveness & 9.6314 & 70.541 & 0.555 & 0.417 & 0.891 \\
\hline BDI 14 & Worthlessness & 9.6431 & 69.876 & 0.554 & 0.429 & 0.891 \\
\hline BDI 15 & Loss of energy & 9.2902 & 69.057 & 0.550 & 0.474 & 0.890 \\
\hline BDI 16 & $\begin{array}{l}\text { Changes in sleep } \\
\text { pattern }\end{array}$ & 9.2667 & 67.740 & 0.484 & 0.360 & 0.893 \\
\hline BDI 17 & Irritability & 9.5882 & 70.613 & 0.486 & 0.345 & 0.892 \\
\hline BDI 18 & Changes in appetite & 9.5647 & 70.711 & 0.394 & 0.372 & 0.894 \\
\hline BDI 19 & $\begin{array}{l}\text { Concentration } \\
\text { difficulties }\end{array}$ & 9.6706 & 71.206 & 0.486 & 0.368 & 0.892 \\
\hline BDI 20 & Tiredness and Fatigue & 9.3294 & 69.175 & 0.555 & 0.534 & 0.890 \\
\hline BDI 21 & Loss of interest in sex & 9.0118 & 67.933 & 0.418 & 0.280 & 0.895 \\
\hline
\end{tabular}

$54.6 \%$ of the sample. Forty six participants were clerks (16.2\%), 108 were business people (38\%) and 130 were unemployed $(45.8 \%)$. Ten percent of the population had bachelor or higher university degrees, $42 \%$ had diploma and associate degrees, $48 \%$ had some school education.

\section{Reliability}

The reported Cronbach's alpha on the internal consistency of the BDI-II was 0.90 and the correlation of each item with the total score ranged from 0.34 to $0.79(\mathrm{p}<0.001)$. The results of item analysis also indicated that alpha was reduced after illuminating items and it was consistent over all items so it was concluded that every item was suitable. (Table 1)

\section{Validity}

The correlation of BDI-II with PHQ-9 and GAD-7 was reported to be 0.74 and 0.65 respectively. Factor analysis was implemented to investigate the construct validity and the result of Kaplan-Meier-Olkin test was 0.90. The Bartlett test proved significant which is an indication of the data being appropriate for factor analysis. Factor analysis results indicated that the questionnaire is of 5 factor loadings where the first factor explains $37.63 \%$ of the variation, the second factor explains $6.10 \%$, the third factor $5.83 \%$ and the fourth and fifth factors explain $5.38 \%$ and $4.97 \%$, respectively, of the variation. The factors totally explain $59.93 \%$ of the variation. (Table 2)

\section{Specification of the test for screening}

To obtain accuracy and the optimal cut-off point, the ROC test was implemented. The results indicated that Beck Depression Inventory covers $0.86(95 \% \mathrm{CI}=0.82-0.90)$ of the area under the curve (Figure 2). This data indicates that the second version of Beck depression inventory can recognize depressed coronary patients from the non-depressed.

According to the Youden index, the optimal cut-off point to diagnose depression in this study, and for research purposes, is 11 with sensitivity 
Table 2. Factor analysis of BDI-II

\begin{tabular}{|c|c|c|c|c|c|c|c|c|c|c|}
\hline \multirow[b]{2}{*}{ Factor } & \multirow[b]{2}{*}{ Cognitive } & \multicolumn{6}{|c|}{ Questions } & \multirow{2}{*}{$\begin{array}{c}\begin{array}{c}\text { Cumulative } \\
\%\end{array} \\
37.63\end{array}$} & \multirow{2}{*}{$\begin{array}{c}\begin{array}{c}\% \text { of } \\
\text { Variance }\end{array} \\
37.63\end{array}$} & \multirow{2}{*}{$\frac{\text { Total }}{7.90}$} \\
\hline & & 1 & 2 & 3 & 7 & 12 & 13 & & & \\
\hline 1 & & 0.52 & 0.52 & 0.56 & 0.77 & 0.44 & 0.61 & & & \\
\hline Factor & Somatic & 11 & 16 & 17 & 18 & 19 & 21 & 43.71 & 6.01 & 1.28 \\
\hline 2 & & 0.61 & 0.49 & 0.67 & 0.50 & 0.63 & 0.49 & & & \\
\hline \multirow{2}{*}{$\begin{array}{c}\text { Factor } \\
3\end{array}$} & Impaired & 4 & 15 & 20 & & & & 49.57 & 5.83 & 1.22 \\
\hline & performance & 0.47 & 0.65 & 0.79 & & & & & & \\
\hline Factor & Negative & 8 & 9 & 14 & & & & 54.95 & 5.38 & 1.13 \\
\hline 4 & $\begin{array}{l}\text { attitude to self } \\
\text { and } \\
\text { worthlessness }\end{array}$ & 0.50 & 0.72 & 0.69 & & & & & & \\
\hline Factor & Self & 5 & 6 & 10 & & & & 59.57 & 4.97 & 1.04 \\
\hline 5 & punishment & 0.74 & 0.80 & 0.52 & & & & & & \\
\hline
\end{tabular}

of 0.78 and specificity of 0.81 . The cut-off point of 10 with sensitivity of 0.80 and specificity of 0.77 is recommended for clinical purposes (Table $3)$.

\section{DISCUSSION}

The internal consistency of BDI-II based on Cronbach's alpha was 0.90. Generally, Cronbach's alpha coefficients higher than 0.70 are considered as significant and coefficients equal or higher than 0.70 are trusted. ${ }^{(23)}$ The present study confirmed previous research carried out on coronary patients in Indonesia that came up with an alpha coefficient similar to ours $(\alpha=0.87){ }^{(11)}$ In a study in the general and hospital population in the Dominican Republic, Cronbach's alpha coefficients were reported between 0.70 to 0.89 . $^{(24)}$

The validity of the inventory was investigated through Pearson correlation of BDI with PHQ-9 and GAD-7, which turned out to be 0.74 and 0.65 respectively, indicating the inventory as valid. The above-mentioned study in Indonesia

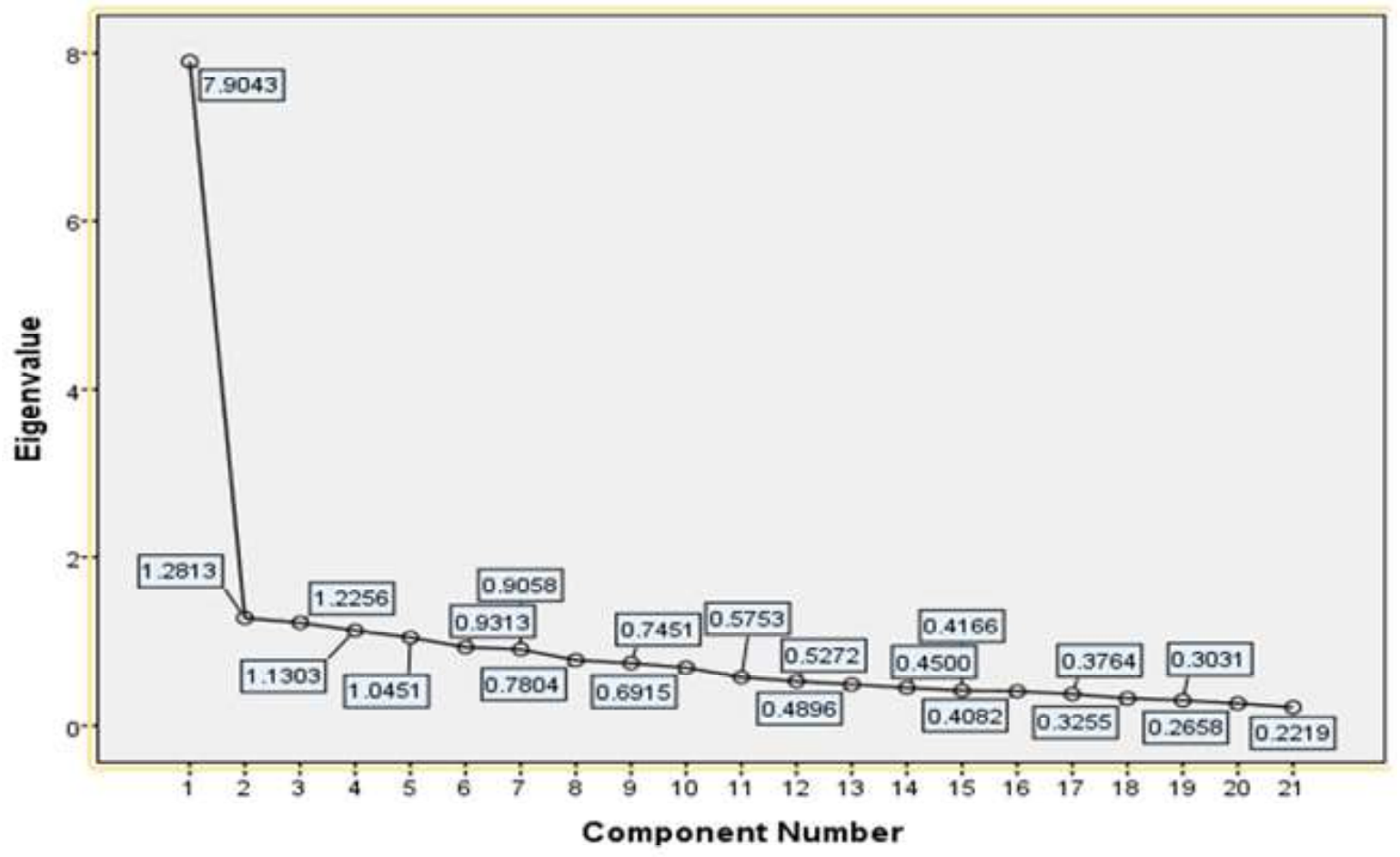

Figure 1. Screen plot for Beck depression inventory 


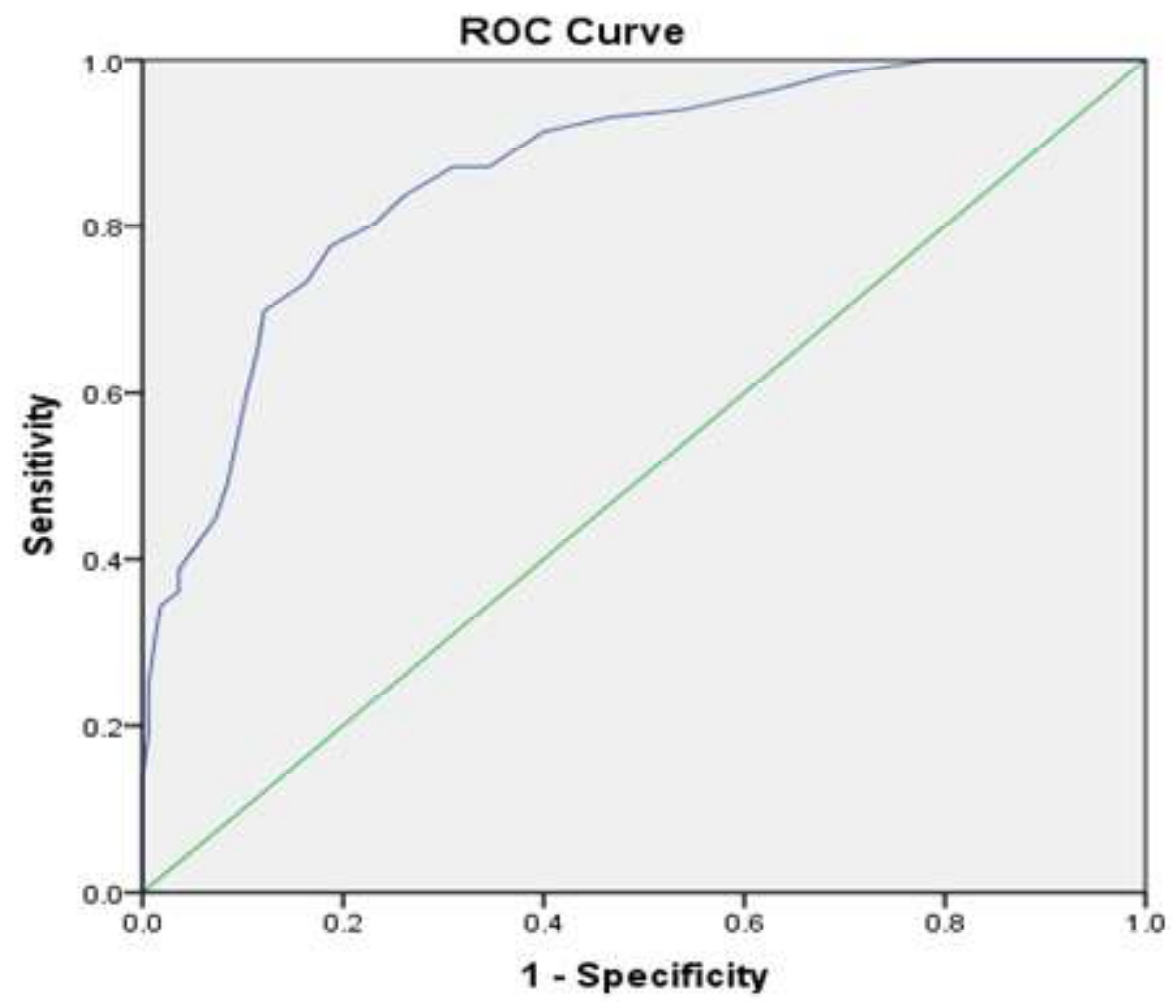

Figure 2. Receiver operating characteristic curve for BDI-II

(11) on coronary patients, and depressed and healthy people investigated the correlation of BDI with questionnaires of type D personality scale (DS14), Beck anxiety inventory (BAI), multidimensional scale of perceived social support (MSPSS), and life orientation test-revised version (LOT-R), yielding correlation coefficients of 0.52 , $0.52,-0.039$ and -0.46 , respectively, which are lower than the values of the present study.

Factorial analysis of BDI implemented for coronary patients led to 5 major factor loadings listed here under the headings ccognitive, somatic, impaired performance, negative attitude to self and, and self punishment. Previous studies, carried out on differing populations, have reported different factor loadings, while previous researches on coronary patients share cognitive, emotional and physical factor loadings with ours. ${ }^{(11)}$ With distinct samples of HIV patients factorial structures of cognitive/emotional and physical as well as factorial structures of negative thoughts, dysfunction and physical signs were

Table 3. Sensitivity, specificity, predictive values, and likelihood ratios at various cut-off scores of the BDI-II

\begin{tabular}{cccccccc}
\hline & Cut-off point & Sensitivity & Specificity & PPV & NPV & LR+ & LR- \\
\hline & $\geq 7$ & 0.78 & 0.66 & 0.63 & 0.87 & 2.52 & 0.19 \\
& $\geq 8$ & 0.78 & 0.69 & 0.66 & 0.88 & 2.81 & 0.18 \\
& $\geq 9$ & 0.84 & 0.74 & 0.69 & 0.86 & 3.20 & 0.22 \\
\multirow{3}{*}{ BDI-II } & $\geq \mathbf{1 0}^{*}$ & $\mathbf{0 . 8 0}$ & $\mathbf{0 . 7 7}$ & $\mathbf{0 . 7 1}$ & $\mathbf{0 . 8 4}$ & $\mathbf{3 . 4 8}$ & $\mathbf{0 . 2 5}$ \\
& $\geq \mathbf{1 1}^{* *}$ & $\mathbf{0 . 7 8}$ & $\mathbf{0 . 8 1}$ & $\mathbf{0 . 7 4}$ & $\mathbf{0 . 8 3}$ & $\mathbf{4 . 1 2}$ & $\mathbf{0 . 2 7}$ \\
& $\geq 12$ & 0.73 & 0.84 & 0.75 & 0.81 & 4.47 & 0.31 \\
& $\geq 13$ & 0.70 & 0.88 & 0.80 & 0.80 & 5.73 & 0.34 \\
& $\geq 14$ & 0.66 & 0.89 & 0.8 & 0.85 & 5.69 & 0.39 \\
\hline
\end{tabular}

*Recommended cut-off points for a two-stage screening (maximal sensitivity and $\geq 75 \%$ specificity)

**Optimal cut-off points according to maximal Youden Index (sensitivity+specificity-1). 
reported. ${ }^{(13)}$ Considering the fact that depression surfaces differently in differing communities, the observed differences can be due to distinct communities.

The results of the ROC curve demonstrated that the AUC of the BDI-II was 0.86 , which is considered good according to the conventional classification system. ${ }^{(25)}$ In the Indonesian study on heart disease mentioned earlier, the AUC was 0.81 , which is similar to that of the present study. ${ }^{(11)}$

The obtained cut-off point in this study was 11 with sensitivity of 0.78 and specificity of 0.81 which indicates the instrument to be suitable for diagnosis and screening purposes. Confirming the present study results, a study on heart patients in Canada reported the optimal cut-off point, independent of demographic variables, as 10 with sensitivity of $83 \%$ and specificity of $73 \%$. ${ }^{(12)}$ In yet another research in Lithuania a cut-off point of 14 with sensitivity of 0.89 and specificity of 0.74 was reported. ${ }^{(26)}$ As well, in a study in Indonesia on depressed, nondepressed and coronary patients, the cut-off point of 17 was obtained with sensitivity and specificity of 0.73 which is a bit different from the results of the present study as well as the two aforementioned studies. ${ }^{(11)}$ It is worth mentioning that the population in Indonesian study was a combination of healthy, depressed and coronary patients and it aimed at diagnosing minimal depression which could explain the different reported cut-off point.

The present study has some limitations that should be taken into consideration. The present sudy investigated the BDI-II in a sample of the patients with CHD; therefore, the findings should be generalized to other populations with caution. Due to the limitations of this study, it is recommended that these questionnaires be studied in a different group of patients.

\section{CONCLUSION}

This study indicated that BDI was of a suitable reliability and validity in patients with coronary heart disease in Iran. In Iran, the cutoff point of 10 could be implemented for clinical purposes and the cut-off point of 11 suits research purposes better.

\section{ACKNOWLEDGMENTS}

This article has been extracted from the thesis written by Seyed Mojtaba Ahmadi in school of Medicine of Shahid Beheshti University of Medical Sciences (registration NO: 377M). The authors of this article would also like to thank all patients who participated in this study.

\section{CONFLICT OF INTEREST}

There is no conflict of interest between the authors.

\section{CONTRIBUTORS}

SMA and AMA contributed to the Study concept and design. SMA, AMA, MB, MHDE, and RM contributed to the analysis and interpretation of data. AMA contributed to the drafting of the manuscript and critical revision of the manuscript for important intellectual content. MB and MHDE contributed to the study supervision. All authors have read and approved the final manuscript.

\section{REFERENCES}

1. Kang HJ, Kim SY, Bae KY, et al. Comorbidity of depression with physical disorders: research and clinical implications. Chonnam Med J 2015;51:818. doi: $10.4068 / \mathrm{cmj} .2015 .51 .1 .8$.

2. Smith HR. Depression in cancer patients: pathogenesis, implications and treatment. Oncol Lett 2015;9:1509-14. doi: 10.3892/ol.2015.2944.

3. Hare DL, Toukhsati SR, Johansson P, et al. Depression and cardiovascular disease: a clinical review. Eur Heart J 2014;35:1365-72. doi: 10.1093/ eurheartj/eht462.

4. Tully PJ, Baumeister H. Collaborative care for the treatment of comorbid depression and coronary heart disease: a systematic review and metaanalysis protocol. Systematic Reviews 2014;3:127. doi.org/10.1186/2046-4053-3-127. 
5. Ren Y, Yang H, Browning C, Thomas S, et al. Prevalence of depression in coronary heart disease in China: a systematic review and metaanalysis. Chin Med J 2014;127:2991-8. doi: 10.3760/cma.j.issn.0366-6999.20140036

6. Ghaemmohamadi MS, Behzadifar M, Ghashghaee A, et al. Prevalence of depression in cardiovascular patients in Iran: a systematic review and meta-analysis from 2000 to 2017 . J Affect Disord 2018;227:149-55. doi: 10.1016/ j.jad.2017.10.026.

7. Carney RM, Freedland KE. Depression and coronary heart disease. Nat Rev Cardiol 2017;14:145. doi: 10.1038/nrcardio.2016.181.

8. Lichtman JH, Froelicher ES, Blumenthal JA, et al. Depression as a risk factor for poor prognosis among patients with acute coronary syndrome: systematic review and recommendations: a scientific statement from the American Heart Association. Circulation 2014;129:1350-69.-69. doi: 10.1161/CIR.0000000000000019.

9. Baird D, Jackson AC, Higgins RO, et al. Screening, assessment and treatment for depression in patients with chronic heart failure. Br J Card Nurs 2018;13:386-93. doi: 10.12968/bjca.2018.13.8.386.

10. Ceccarini M, Manzoni GM, Castelnuovo G. Assessing depression in cardiac patients: what measures should be considered? Depres Res Treat 2014; Article ID 148256, 17 pages. DOI: http:// dx.doi.org/10.1155/2014/148256(3):148256.

11. Ginting $H$, Näring $G$, van der Veld $W M$, et al. Validating the Beck depression inventory-II in Indonesia's general population and coronary heart disease patients. Int J Clin Health Psychol 2013;13:235-42. doi:10.1016/S1697-2600(13)700280 .

12. Moullec G, Plourde A, Lavoie KL, et al. Beck depression inventory II: determination and comparison of its diagnostic accuracy in cardiac outpatients. Eur J Prev Cardiol 2015;22:665-72. doi: $10.1177 / 2047487314527851$.

13. Abubakar A, Kalu RB, Katana K, et al. Adaptation and latent structure of the Swahili version of Beck depression inventory-II in a low literacy population in the context of HIV. PloS One 2016;11:e0151030. doi: 10.1371/journal.pone. 0151030.

14. Tajfard M, Ghayour-Mobarhan M, Rahimi HR, et al. Anxiety, depression and coronary artery disease among patients undergoing angiography in Ghaem hospital, Mashhad, Iran. Health 2014; 6:1108. doi: 10.4236/health.2014.611137.
15. Abbasi SH, Kassaian SE, Sadeghian S, et al. Factors associated with depressive symptoms in young adults with coronary artery disease: Tehran heart center's premature coronary atherosclerosis cohort (THC-PAC) study. Iran J Psychiatry 2016; 11:214-23.

16. Najafipour H, Banivaheb G, Sabahi A, et al. Prevalence of anxiety and depression symptoms and their relationship with other coronary artery disease risk factors: a population-based study on 5900 residents in Southeast Iran. Asian J Psychiatr 2016;20:55-60. doi: 10.1016/j.ajp.2016.01. 004.

17. Wang YP, Gorenstein C. Psychometric properties of the Beck depression inventory-II: a comprehensive review. Braz J Psychiatry 2013;35:416-31. doi: 10.1590/1516-4446-2012-1048.

18. First MB, Williams J, Karg RS, et al. User's guide to structured clinical interview for DSM-5 disorders (SCID-5-CV) clinical version: Arlington, VA: American Psychiatric Publishing; 2015.

19. Beck AT, Steer RA, Brown GK. Manual for the Beck depression inventory-II. San Antonio, TX: Psychological Corporation;1996.

20. Kroenke K, Spitzer RL, Williams JB. The PHQ 9: validity of a brief depression severity measure. J Gen Intern Med 2001 ;16:606-13. doi:10.1046/j152514972001016009606x

21. Spitzer RL, Kroenke K, Williams JBW, et al. Abrief measure for assessing generalized anxiety disorder: The GAD-7. Arch Intern Med 2006;166:1092-7. doi:10.1001/archinte.166.10.1092

22. Lowe B, Spitzer RL, Grafe K, et al. Comparative validity of three screening questionnaires for DSM-IV depressive disorders and physicians' diagnoses. J Affect Disord 2004;78:131-40. 6723

23. Hinton PR. Statistics explained. $3^{\text {rd }}$ ed. UK: Routledge; 2014.

24. García-Batista ZE, Guerra-Peña K, Cano-VindelA, et al. Validity and reliability of the Beck depression inventory (BDI-II) in general and hospital population of Dominican Republic. PloS One 2018;13:e0199750. doi: 10.1371/journal.pone. 0199750 .

25. Safari S, Baratloo A, Elfil M, et al. Evidence based emergency medicine; Part 5 receiver operating curve and area under the curve. Emergency 2016;4:111-3.

26. Bunevicius A, Staniute M, Brozaitiene J, et al. Diagnostic accuracy of self-rating scales for screening of depression in coronary artery disease patients. J Psychosom Res 2012;72:22-5. doi: 10.1016/j.jpsychores.2011.10.006. 